\title{
FATIGUE DEGRADATION OF THE STRUCTURE OF PARACHUTE SYSTEMS
}

\author{
Krzysztof Szafran $^{1}$, Ireneusz Kramarski ${ }^{2}$ \\ ${ }^{1}$ Institute of Aviation, Warsaw, Poland \\ ${ }^{2}$ HORNET, Nowy Dwór Mazowiecki, Poland \\ krzysztof.szafran@ilot.edu.pl
}

\begin{abstract}
Parachute systems are in widespread use in aviation. Up to now, parachutes are the most uncertain air vehicles because of their complex and unsteady opening characteristics, changes in geometry up to $30 \%$ and vulnerability from unsteady atmospheric turbulence. Fatigue is a problem that the designers of long living parachute systems need to cope with. Authors demonstrate complexity of parachute exploitation and means to lower opening forces and extend service life without influencing safety.
\end{abstract}

Keywords: Parachute systems, fatigue degradation, aviation safety system

\section{INTRODUCTION}

Parachute systems are in widespread use in aviation. Ranging from sport parachutes (skydiving, free flying, wing suit flying, base jumps, tandem flying etc.), to emergency parachutes (crew members, all fuselage) to various many military purposes (troop deployment, braking of warplanes during landing, deployment of bombs, flares, torpedoes and mines), parachutes are ubiquitous in our world.

The parachute is a special flying object which, in contrast to other aircraft, should create as much drag as possible in the air during descending. Additionally, the parachute should have stability during descending without excessive swinging. Also, the parachute should have the lowest possible weight and volume as low as possible. All the above requirements have to be fulfilled by a structure with folding capability and with capability of proper unfolding without excessive forces during inflation in the high range of speeds. For civil reserve and emergency parachutes, 
maximum opening speed is 150 KTS. For parachutes designed for planetary entrance, those speeds are exceeding the speed of sound. In military applications, the parachute deployment speed of can reach supersonic speed.

\section{ENVELOPE STRUCTURE OF PARACHUTE}

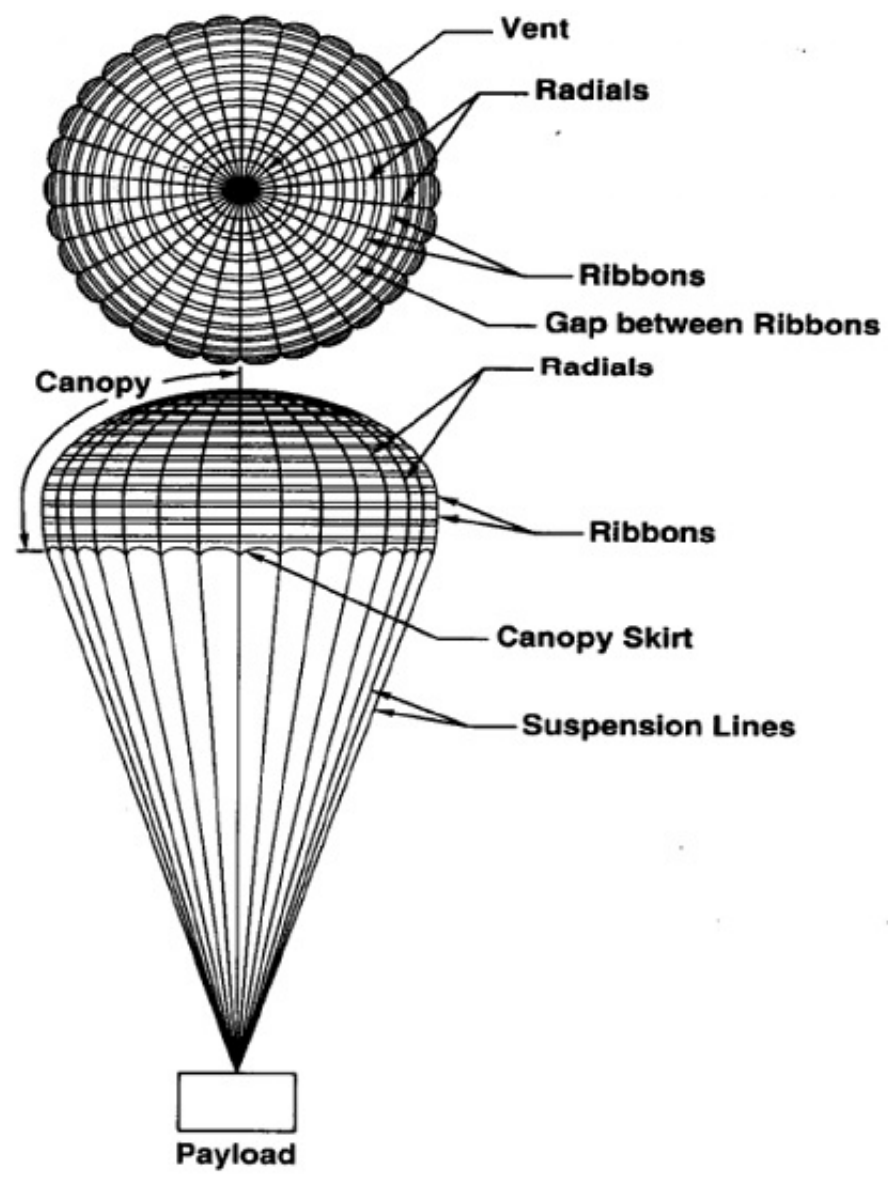

Fig. 1. Elements of parachute [1]

To meet the requirements mentioned above parachutes are designed as envelope structures with supporting parts including suspension lines, linking tapes, covers etc. (Fig. 1). Parachutes are manufactured with using a wide range of textiles. The canopy is made of the fabric with radial and perimeter (ribbons) reinforcements made of tapes. The canopy is linked with the payload with a group of suspension lines. There are also certain suspension tapes used to connect suspension lines (and the canopy) to the payload. A parachute 
system is folded into special covers for protection. The jointing technology as well as materials and their technical parameters also used in the construction of aerostats are quoted in [2].

Parachutes are designed to properly deploy from the folded condition, withstand opening forces with loads accepted for the jumper or the payload and generate enough drag to ensure that the descending speed is sufficiently low to protect the jumper or other payload from injury or being damage during landing.

During the inflation process the parachute canopy rapidly changes its geometry which affects the air stream and generates unsteady coupling between the inflation parameters. Every change in the canopy geometry directly changes the air flow around the canopy causing quick and non-linear changes in drag force.

Moreover, textile materials used in parachute systems have very high elongation characteristics of up to $30 \%$ during the opening process. This is a very important parameter to be considered in any analysis and calculations.

\section{FATIGUE IN PARACHUTE SYSTEMS}

\subsection{One use with one folding of the parachute system}

Here belong parachute systems used in reentry vehicles. Apollo or Soyuz reentry vehicles use parachute systems designed to bring astronauts safely to Earth after a space mission has been completed. Those parachute systems do not demonstrate fatigue because of folding just before the mission and due to only one opening.

A special case is the parachute systems used in entry and descending in Solar system planetary missions. It is possible to damage the parachute system during a few year long mission to a distant planet.

\subsection{One use with numerous folding of the parachute system}

Here belong emergency parachute systems like back/chest/chair emergency parachutes for crew members, reserve parachutes for skydivers and troops, parachutes for ejector seats and parachutes for all airframe rescue. Because of the characteristic of textile materials it is mandatory to repack the parachute system. For emergency and reserve parachutes the repack time is from 6 to 12 months. For ejector seats the repack time can be up to 3 years. For all airframe rescue the repack time is from 12 to 36 months.

Consequently, potential fatigue issues may arise from folding and repetitive folding during life. It is typical that during folding the same parts of a parachute tend to be treated in the same manner. So the same parts of the canopy are folded in the same manner, and the same parts of suspension lines are bent at each folding/ packing process. Bending parachute parts over and over at the same points can degrade their performance at those points and cause malfunction during opening. 
Based on the experiences of the Belgian army, the Hang Gliding and Paragliding Association of Canada as well as the Parachute Industry Association (PIA) [6], have acknowledged this problem and recommended that time intervals between consecutive repacking procedures for emergency and reserve parachutes should be extended as much as it is possible.

It should be mentioned that emergency and reserve parachutes are packed into soft containers so during exploitation i.e. ingress and egress to the cockpit in the case of crew members and during ingress and egress to the airplane in the case of skydivers, soft containers can be under some loads affecting the parachutes stored inside. This does not concern ejector seat parachutes, which are stored inside the hard structure of the ejection seat.

\subsection{Numerous use with numerous folding of the parachute system}

This category embraces different types of sport parachutes and troops parachutes, and cargo parachutes.

As for sport and troops parachutes they are especially fatigue prone as they are designed to be used in hundreds of jumps.

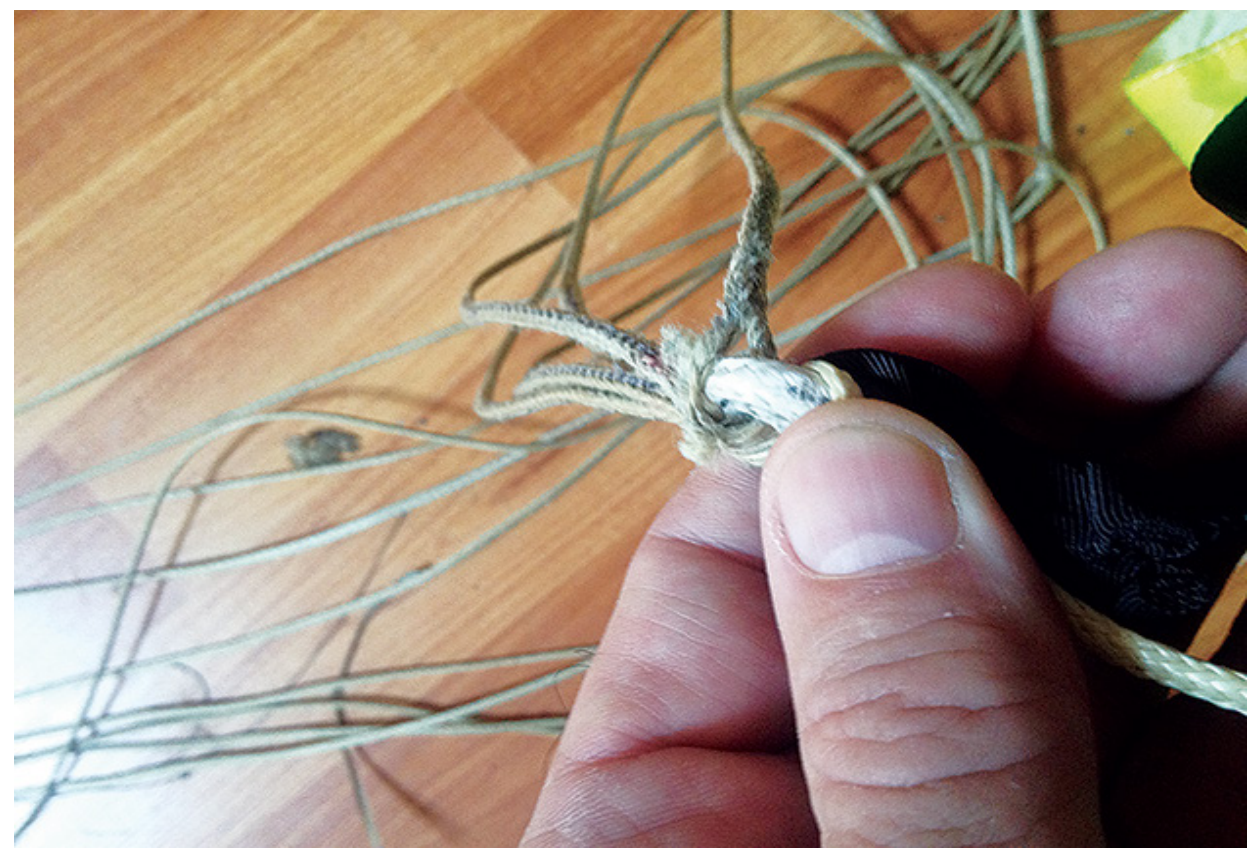

Fig. 2. Severe wear on Vectran Lines [3] 


\section{* Strength Loss - Dacron 525}
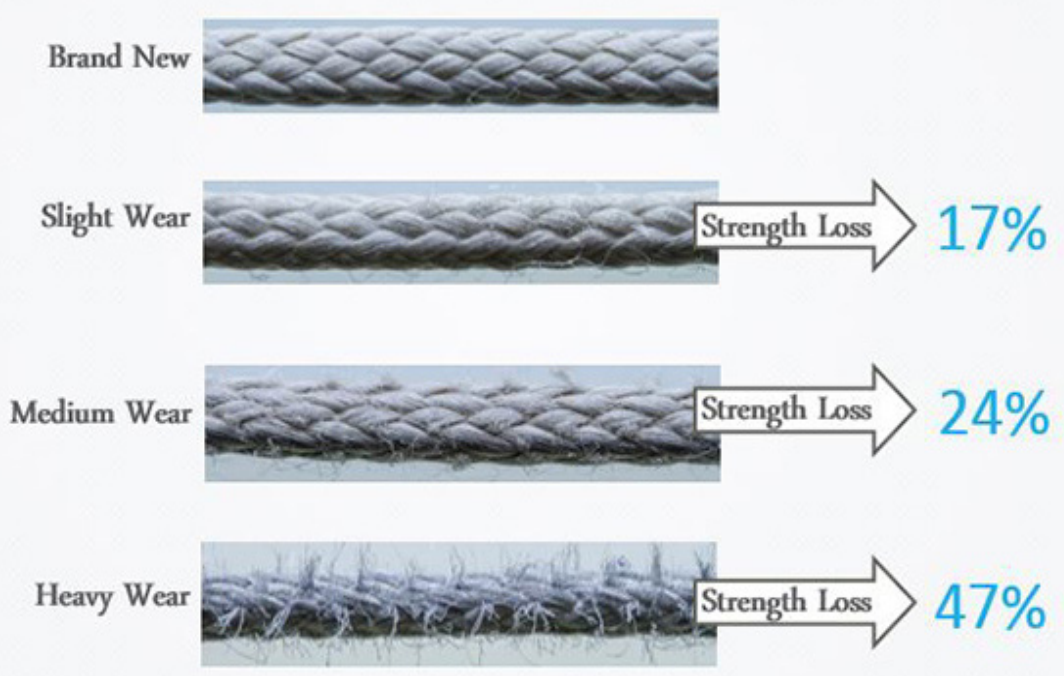

Fig. 3. Strength loss on Dacron 525 lb. parachute lines [3]

The parachute's producer replaces suspension lines according to recommendations. For instance, suspension lines in ramair parachutes from Dacron can withstand up to 800 jumps, from Spectra up to 600 jumps and from Vectran up to 400 jumps in medium wear conditions.

Life span also strongly depends on the landing zone environment. So the "heavy wear" examples of Dacron lines could have 200 jumps in a desert environment or they could have 800-1200 jumps in a grassy environment with a clean packing area.

Materials used for most lines these days include Dacron ${ }^{\circledR}$ polyester, Spec$\operatorname{tra}{ }^{\circledR}$ (aka microline), Vectran ${ }^{\circledR}$ and high-modulus aramid (HMA) lines.

Dacron has the most elasticity, but is bulky and abrades easily.

Microline is the most abrasion-resistant, yet it is prone to heat shrinkage and going 'out of trim'.

Vectran is very dimensionally stable (will hold its trim), but abrades fairly easily.

HMA is dimensionally stable with less drag compared to Vectran. It abrades fairly easily, too.

Example from SIGMA Tandem System Owner's Manual [8] 


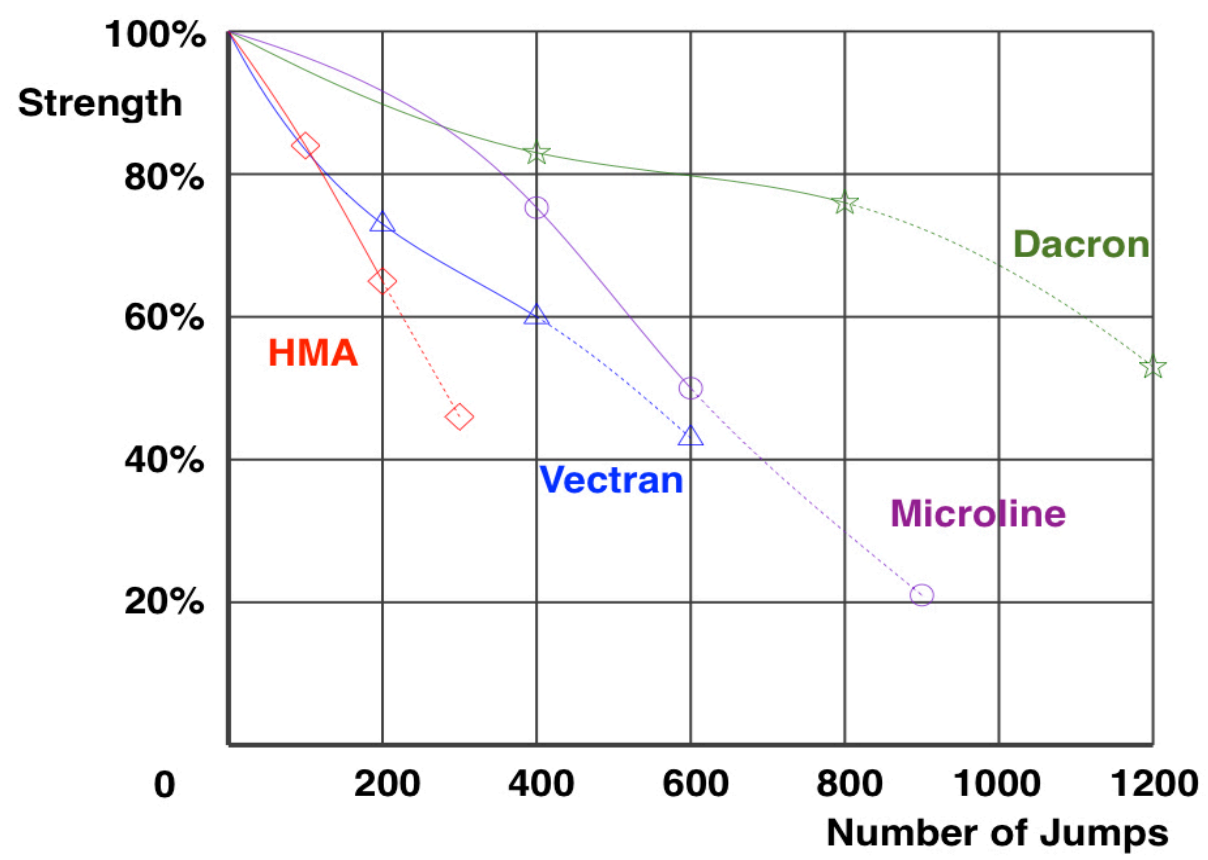

Fig. 4. Strength loss of parachute lines relative to number of jumps.

Continuous lines represent loss of strength from new condition to medium wear condition. Doted lines show losses of strength from medium wear to heavy wear.

Lines with medium wear should be replaced.

\section{RECOMMENDED COMPONENT LIFESPANS}

The following recommendations have been established based on the estimated lifespan of Sigma Tandem components. It is important to ensure that an appropriately rated rigger determines if the components are in an airworthy condition.

- Replace main canopy suspension lines every 350-500 jumps as needed.

- Replace main canopy every 1400 - 1600 jumps.

- Replace main risers every 600 jumps.

- Replace drogue centerline every 300 jumps.

- Replace the lower Drogue Bridle every 300 jumps.

- Replace drogue every 600 jumps.

\section{RESERVE COMPONENT LIFESPANS}

- Reserve canopy is limited to 25 uses, 40 pack jobs or 20 years in service, whichever comes first.

- Reserve Pilot Chute limited to 25 uses.

- R.S.L and Skyhook limited to 25 uses. 


\section{FATIGUE INFLUENCE REDUCTION}

\subsection{Special canopy design}

To lower opening forces it is feasible to increase the porosity of the parachute canopy. It can be achieved with a fabric with a higher porosity or by the use of the special canopy design with a high geometric porosity, or by combining both methods. For example, a ribbon canopy is made from system of radial and perimeter tapes with high geometric porosity, which allows for relatively smooth openings. Additionally, during the opening process the perimeter tapes can fold longitudinally to lower the drag area. When the opening process nears completion with all tapes and suspension lines stretched, the perimeter tapes unfold and increase the drag area. But compared to other types of canopies, the ribbon canopy generates a low drag during descending in relation to its mass and packed volume. So this type of parachute canopy is used for high loads at high subsonic and middle supersonic speeds and for braking of warplanes during the landing run.

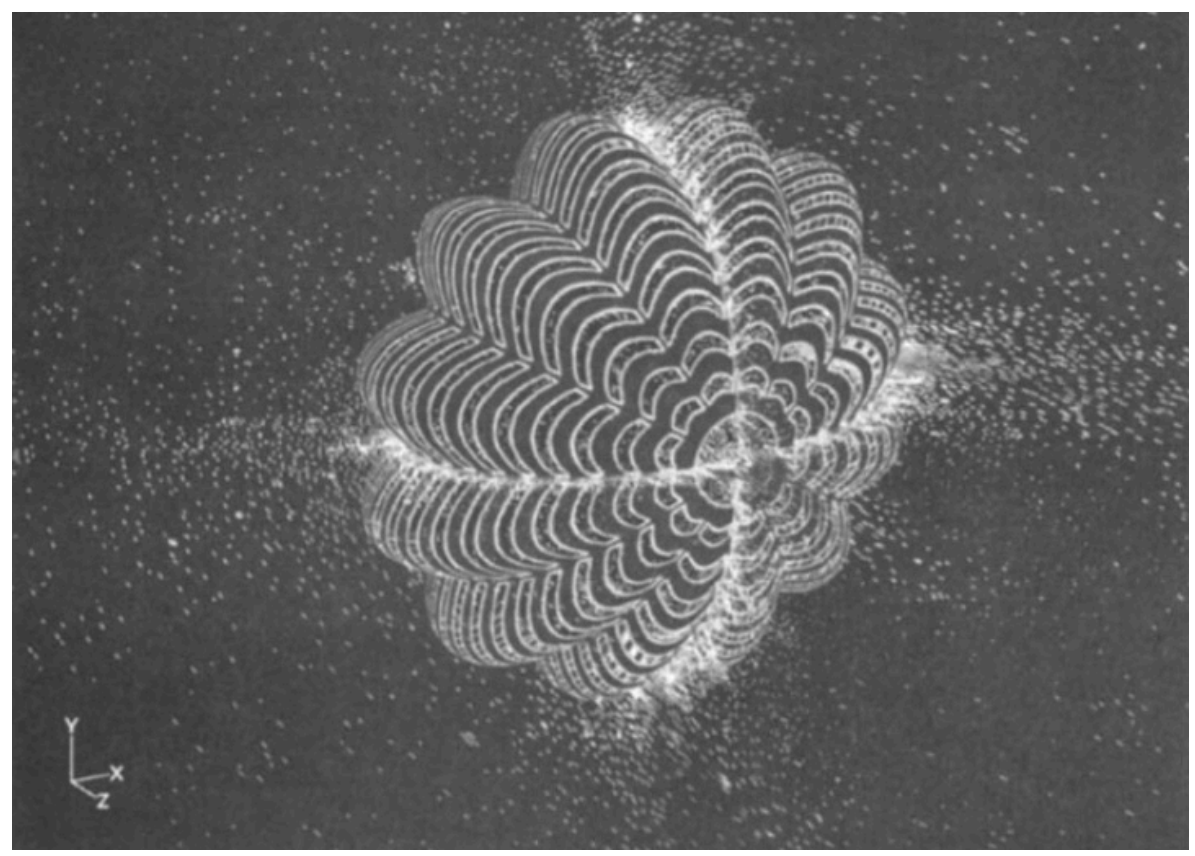

Fig. 5. CFD calculation of 12-gore 12-ribbon parachute (Nelsen 1995) [7]

\subsection{Reefing lines}

For more drag efficient canopies some types of solutions for slowing down the opening process known as reefing devices were designed. 


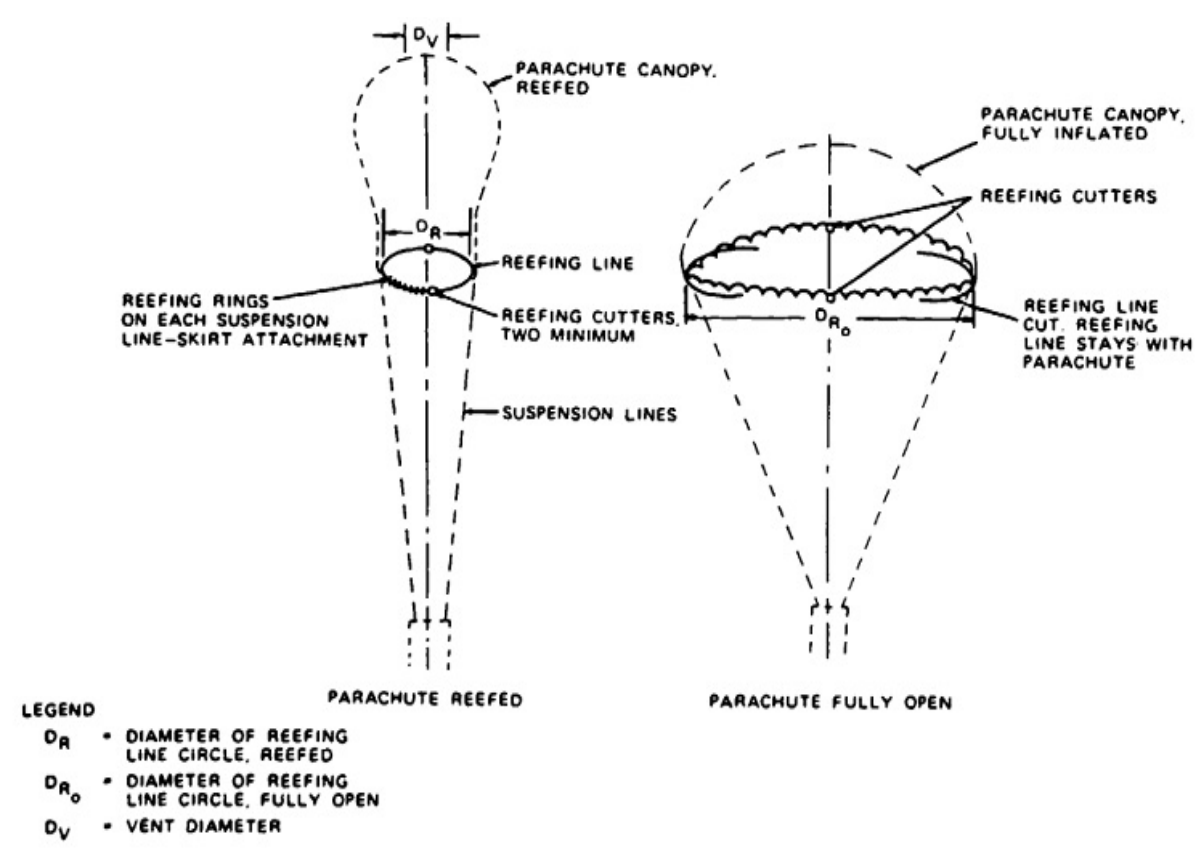

Fig. 6. Parachute reefing with a skirt reefing line [3]

A reefing line or lines go around the skirt of parachute canopy. The line is shorter than the perimeter of the skirt. During opening the inflation is stopped for a while because the reefing line prevents the canopy skirt from increasing its length. During this stage of the opening process the parachute canopy cannot increase, so the drag area is constant and loads cannot increase either. It is possible to reduce the opening loads to the acceptable level by controlling the reefing line in length.

After a preplanned delay, typically 3-5 seconds, the pyrotechnic cutters cut the reefing line and the canopy can expand during inflation - so called dereefing. For each line there are at least two cutters for redundancy of cutting system. But the delay causes rapid lower of the speed and the rest of canopy opening process occurs at lower speeds, so with lower loads.

In more sophisticated parachute systems, for instance in those for reentry manned vehicles (Apollo, Orion), there are two or three reefing lines of different length which allows staging of the opening process. At the first stage, the shortest reefing line stops the canopy from expanding. After a few second delay the cutters cut this line and the canopy can expand to size allowed by the second, longer, reefing line. Following the next delay the cutters cut the second reefing line and the canopy can expand to its maximum. 


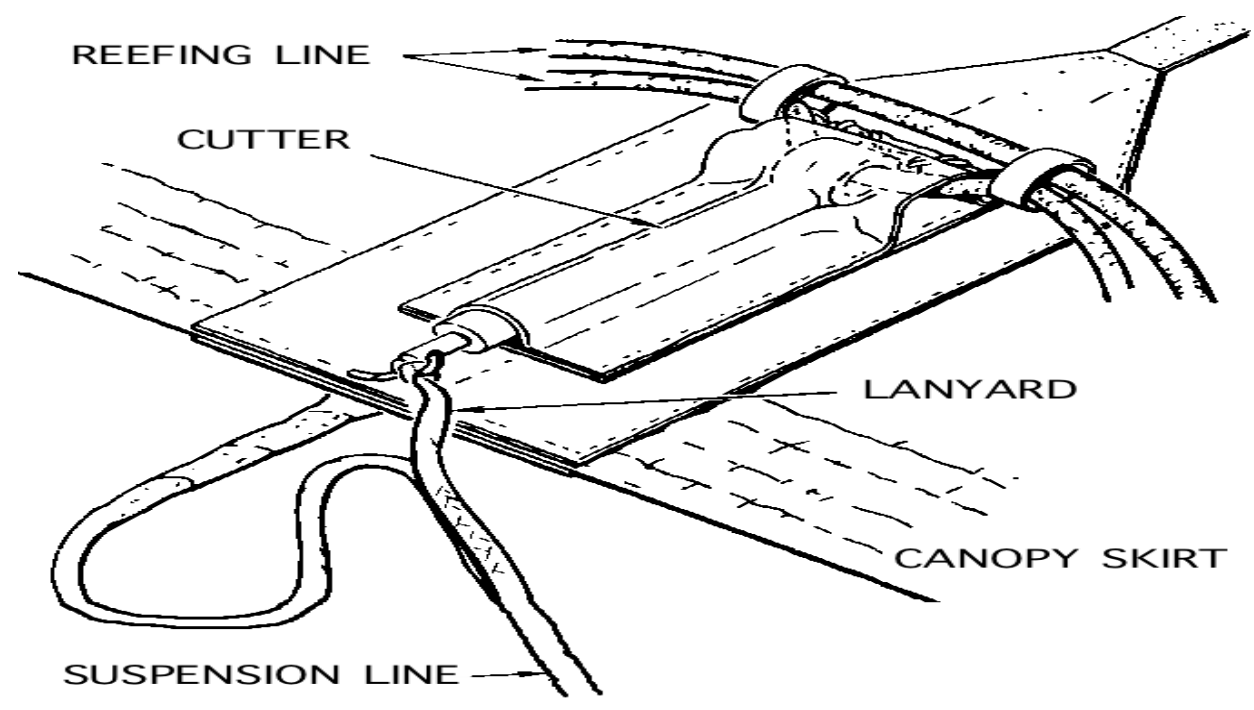

Fig. 7. Arrangement of reefing lines and cutter device [7]

\subsection{Slider}

The slider is a reefing device which interacts with the lines but not with the canopy. It is a piece of fabric with reinforcing tapes on its sides. In ramair parachutes (Parafoils) it is typically rectangular. In round canopies, it is in the shape of a ring.

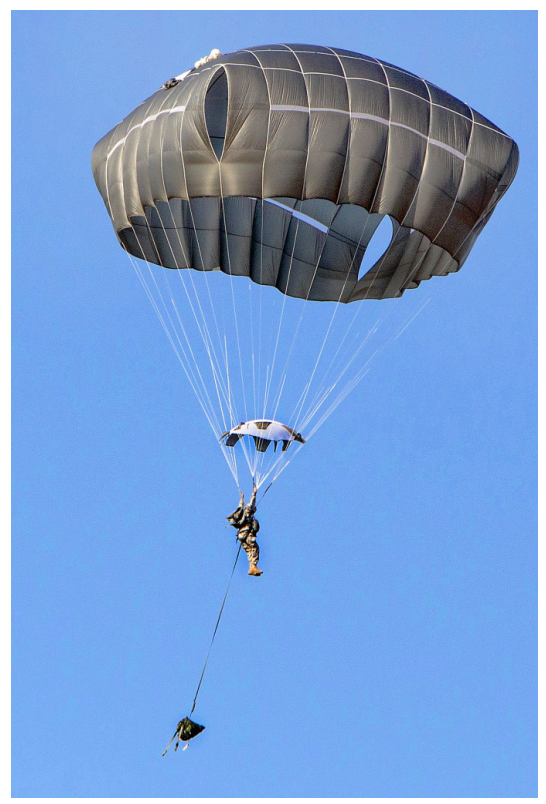

Fig. 8. US troop parachute T-11 with a round slider device [5] 
The slider uses a system of steel grommets. In rammer parachutes, there are four grommets on each apex of the rectangle. The suspension lines of the ram air canopy fall into four groups with each group of the lines going through a hole in the adjacent grommet. So, a few lines are going through the grommet simultaneously scraping against each other and against the inside surface of the hole in the grommet. In round canopies, it is common to put only one suspension line to its own grommet in the slider.

The slider is a very efficient reefing device, especially in ramair canopies which have very rapid opening and very high opening forces. First ramair canopies used reefing lines attached to their pilot chutes. But this led to fatigue dramatically reducing life of reefing lines.

To fight fatigue of suspension lines a number of solutions can be used as listed below:

1. replacing brass or steel with zinc cover grommets for stainless steel grommets (brass is rather soft compared to steel; steel with zinc cover is prone to zinc damage when the lines are sliding inside the grommet while any damage cover produce sharp edges which can quickly destroy the suspension lines; stainless steel has not any additional cover so its surface can last longer without any damage or corrosion);

2. controlling of the speed of opening by using sliders with greater porosity by using fabric or utilizing geometric porosity; the slider during its run can generate drag force so its porosity and size can affect the speed of the canopy's opening;

3. using new types of textile materials (fabrics, ropes for suspension lines, tapes, threads etc.), the development of which is being propelled by a large-scale use of parachutes with sliders in civil and in military application;

4. following advances in understanding of complex, unsteady and interactive processes during parachute opening, which allows the honing of parachute's designs and planning new research activities.

5. active systems, which are undoubtedly dynamically controlled parachutes, require additional theoretical research [10].

\section{CONCLUSIONS}

Fatigue is a problem that the designers of long living parachute systems need to cope with. Although fatigue does not concern singular use parachutes, parachutes used for hundreds of jumps have a special design and devices for lowering loads during opening and by this mean to lengthen their life span. Actually, the most efficient device for reefing a parachute's canopy i.e. slowing its opening time is a slider. Advances in textile materials coupled with a better understanding of parachute inflation, new methods of computational simulating and results from real world testing can all create the foundation for development of parachute systems which offer 
higher performances and are less fatigue prone. The principles of long-term storage of military equipment and algorithms to maximize reliability and safety of use are shown in [11]; some of them may be applied to parachute systems used irregularly in which problems of fatigue materials are transformed by aging.

\section{BIBLIOGRAPHY}

[1] Peterson, C. W., Strickland, J. H., Higuchi, H, 1996 "The Fluid Dynamics of Parachute Inflation, Annual Review of Fluid Mechanics, Volume 28 (1) - Jan 1.

[2] Szafran K., Kramarski I. 2015 "Safety of Navigation on the Approaches to the Ports of the Republic of Poland on the Basis of the Radar System on the Aerostat Platform". Trans Nav the International Journal on Marine Navigation and Safety of Sea Transportation. ISSN 2083-6473 vol. 9 nr 1 pp. 131-136.

[3] http://blog.performancedesigns.com/know-your-lines-part-3-when-do-youneed-a-reline/

[4] Nelsen, J. M., Computational fluid dynamic studies of a solid and ribbon $12-$ gore parachute canopy in subsonic and supersonic flow. 13th AIAA Aerodynamic Decelerator Systems Technology Conference, AIAA Paper 95-1558

[5] Parachute Handling vs Porosity ( https://www.hpac.ca/pub/?pid=158)

[6] PIA Position On A 180 Day Repack Cycle http://www.pia.com/piapubs/ pia_position_on_a_180_day_repack.htm

[7] Knacke, T., W., Parachute Recovery Systems Design Manual, 1991

[8] SIGMA Tandem System Owner's Manual (http://unitedparachutetechnologies. com/PDF/Support/Manual/Manual_Sigma_MAN-013.pdf?Name=Value)

[9] Szafran K., Pągowski Z.T. \& Kramarski I. 2015 „Badania symulacyjne elementów konstrukcyjnych modułowego napędu platformy badawczej”. Trans Comp 2015, TTS - ISSN 1232-3829 12/2015 pp. 234-241

[10] Kasyanov V.A., Szafran K., Goncharenko A., Shipitiak T. „Entropy Paradigm in the theory of Hierarchical Active Systems. Elements of Conflict Theory". Transaction of the Institute of Aviation. № 5-6 (232-233). - pp. 115-128. 2013

[11] SzafranK., KończakJ.,M.Mieteń2017,,Impactofthedecision on transportsystems' reliability in emergency situations". DOI: 10.5604/01.3001.0010.7230, JOURNAL OF SCIENCE OF THE MILITARY ACADEMY OF LAND FORCES. Volume 49 Number 4(186) 